\title{
INFLUENCE OF TIDAL VOLUME, RESPIRATORY RATE, AND SUPPLEMENTAL OXYGEN FLOW ON DELIVERED OXYGEN FRACTION USING A MOUTH TO MASK VENTILATION DEVICE
}

\author{
John M. Palmisano, RRT, Frank W. Moler, MD, MS, Catherine Galura, RRT, Mark Gordon, RPT, \\ and Joseph R. Custer, MD \\ Department of Pediatrics, Division of Pediatric Critical Care and Department of Respiratory Therapy, C. S. Mott Children's hospital, \\ University of Michigan Medical Center \\ Reprint Address: John M. Palmisano, Department of Pediatrics, C. S. Mott Children's Hospital, 1500 E. Medical Center Drive, \\ D-1220 MPB, Box 0718, Ann Arbor, Ml 48109-0718
}

\begin{abstract}
$\square$ Abstract - We examined the influence of the following parameters in determining the $\mathrm{FiO}_{2}$ delivered to a pediatric lung model using the mouth-to-mask method of resuscitation: rate of ventilation, inspiratory tidal volumes, and supplemental oxygen flow. With a ventilator rate of 20 / min and tidal volumes $\left(V_{t}\right) \leq 100 \mathrm{~mL}$, an $\mathrm{FiO}_{2}$ of approximately .50 was observed with a supplemental oxygen flow of $5 \mathrm{~L} / \mathrm{min}$. Increasing the supplemental oxygen flow to 15 $\mathrm{L} / \mathrm{m}$ did not appreciably increase the $\mathrm{FiO}_{2}\left(\mathrm{FiO}_{2}=.53\right.$ versus $\mathrm{FiO}_{2}=.60$, respectively), but did cause a significant and unintended increase in $V_{1}$. Similar results were noted with a ventilator rate of $12 / \mathrm{min}$ and $V_{\mathrm{t}} \leq 100 \mathrm{~mL}$ $\left(\mathrm{FiO}_{2}=.68\right.$ versus $\mathrm{FiO}_{2}=.73$, respectively $)$. We also observed a potentially hazardous situation involving the positioning of the supplemental oxygen port that might result in high inspiratory pressures (stacking of breaths) to the pediatric patient. We believe additional testing is warranted prior to widespread use of this device in children.
\end{abstract}

$\square$ Keywords - mouth-to-mask ventilation; pediatrics; cardiopulmonary resuscitation; oxygen

\section{TNTRODUCTION}

Studies (1-4) using "traincd" medical personnel have detailed the difficulties encountered in single rescuer ventilation using the bag-valve-mask technique. Although the bag-valve-mask delivers a greater $\mathrm{FiO}_{2}$ than mouth-to-mask, these studies indicate that a significantly smaller tidal volume $(509 \mathrm{~mL})$ is delivered by "inexperienced" personnel when compared to endotracheal intubation $(1193 \mathrm{~mL})$ and mouth-to-mask ventilation (1093 $\mathrm{mL})(3)$.

The etiology of cardiorespiratory arrest in adults is most often a cardiac dysrhythmia. In children, cardiorespiratory arrest most often results from hypoxia secondary to apnea or respiratory failure. In both instances assisted manual resuscitation by mouth-tomouth, bag-valve-mask, or mouth-to-mask is recommended until the return of spontancous respiration or until a more permanent form of airway management (that is, endotracheal intubation) can be established (5).

Mouth-to-mouth resuscitation is a riethod of resuscitation that does not allow for supplemental oxym gen administration. The $\mathrm{FiO}_{2}$ administered by this route is approximately $16 \%$. For the pediatric patient who has arrested because of hypoxia, this $\mathrm{FiO}_{2}$ may not be sufficient.

A perceived risk of infection when performing mouth-to-mouth resuscitation on unknown victims has developed among health care employees even though transmission of the human immunodeficiency virus or hepatitis $B$ virus has not been documented $(6-7)$. Because of these concerns, bag-valvemask or mouth-to-mask ventilation has been recommended when possible. Bag-valve-mask ventilation provides supplemental oxygen delivery and limits direct skin contact with the victim; mouth-to-mask resuscitation has been reported in adult models to de- 
liver a greater tidal volume than either bag-valvemask or mouth-to-mouth ventilation when used by both "trained" and "untrained" rescuers (1-2).

Mouth-to-mask resuscitation is a process in which the forced exhalation of the rescuer is delivered through a face mask, which is held firmly over the patient's mouth and nose. Modifications to this device can provide other advantages when compared with mouth-to-mouth resuscitation. These include 1) protective filters and one-way valves that theoretically lessen the incidence of exposure to gastric secretions or infectious agents, and 2) supplemental oxygen adaptors to increase oxygen delivery to the patient. A possible limitation in the use of the mouthto-mask device has been the inability to deliver supplemental oxygen $>80 \%$ (6). An $\mathrm{FiO}_{2}$ from .34 to .81 may be attained with oxygen flows ranging from 2 to $14 \mathrm{~L} / \mathrm{min}$ depending upon the particular product and subsequent modifications (8).

Although the use of the mouth-to-mask device with large tidal breaths has been reported in adult models (1-2), its use in a pediatric model, requiring smaller tidal breaths, has not been investigated. We examined the influence of the rate of assisted ventilation, tidal volume, and supplemental oxygen flow on the $\mathrm{FiO}_{2}$ delivered to a pediatric lung model using a mouth-to-mask device.

\section{MATERIALS AND METHODS}

The mouth-to-mask device (Intertech Resources, Inc., Bannockburn, IL) in use at our institution consists of a mouth piece, $50-\mathrm{mL}$ corrugated extension tube, respiratory filter, one-way "duckbill" valve, exhaust valve, and a standard resuscitation mask (Figure 1A). This device has been adapted to incorporate a supplemental oxygen delivery port. This port may be inserted either between the mouth piece and the one-way valve (Figure 1B) or between the face mask and the one-way valve (Figure $1 C$ ).

A pediatric ventilator (Bird VIP, Bird Product Corporation, Palm Springs, CA) with a standard ventilator circuit (BabyFlex Ventilator Circuit, Baxter Health-Care Corporation, Valencia, CA) was used to simulate rescue breathing and to provide consistent breaths. The humidifier was removed from the circuit to eliminate compressible volume loss. The respiratory pattern was maintained in the volume control mode, with a ventilator flow rate of $20 \mathrm{~L} /$ min. Incremental tidal volumes from 50 to $700 \mathrm{~mL}$ at both 12 and 20 breaths per minute were examined. Volumes $\geq 750 \mathrm{~mL}$ could not be achieved with this ventilator and were not examined. For each of the above parameters, supplemental oxygen was delivered through the mouth-to-mask device at flow rates of $5 \mathrm{~L} / \mathrm{min}, 10 \mathrm{~L} / \mathrm{min}$, or $15 \mathrm{~L} / \mathrm{min}$ from a Thorp tube connected to a standard wall oxygen outlet. The face mask of this device was removed and a test lung was connected at that location (Life Mode Training Test Lung, Grand Rapids, MI). The compliance of the test lung was $0.05 \mathrm{~L} / \mathrm{cm} \mathrm{H}_{2} \mathrm{O}$. Tidal volumes delivered through the mouth-to-mask device were verified by serial measurements on the test lung. An oxygen analyzer (Instrumentation Laboratories 408, Lexington, MA) was calibrated to both $21 \%$ and $100 \%$ (accuracy $\pm 1 \%$ ) and was inserted between the test lung and supplemental oxygen port. Mean $( \pm \mathrm{SD})$ values for high and low $\mathrm{FiO}_{2}$ for 6 consecutive tidal breaths at each oxygen flow rate, respiratory rate, and tidal volume were recorded.

Data were analyzed using Systat version 5.0 for the Macintosh Computer (Systat Inc., Evanston, IL). Six measurements were obtained for all measurements of $\mathrm{FiO}_{2}$ and actual tidal volume delivered. All data are presented as the mean and SD of the minimum delivered $\mathrm{FiO}_{2}$ for a given oxygen flow rate, ventilator rate, and tidal volume. A Mann-Whitney rank sum test was used for the continuous variable comparisons of $\mathrm{FiO}_{2}$ Delivered between groups (Table 1 and Table 2), and an independent $t$ test was used for tidal volumes delivered at tidal volumes of 5,10 , and $15 \mathrm{~L}$ of supplemental oxygen (Table 3 ).

\section{RESULTS}

We originally planned to examine the $\mathrm{FiO}_{2}$ delivered to the test lung with the supplemental oxygen port inserted in two locations: between the mouth piece and the one-way valve (Figure 1B) and between the one-way valve and the face mask (Figure 1C). However, it was observed that passive exhalation was prohibited when the supplemental oxygen port was located above the one-way valve (as depicted in Figure 1B), and supplemental oxygen was delivered. This occurred because supplemental oxygen flow through the one-way valve was sufficient to keep the low resistance one-way valve open and the expiratory valve closed. Because of this observation, the supplemental oxygen port was removed and reinserted between the mask and the one-way valve. All reported values were obtained with the supplemental oxygen port located in this location (Figure 1C).

At a ventilation rate of $20 / \mathrm{min}$, large tidal volumes $\left(V_{\mathrm{t}} \geq 300 \mathrm{~mL}\right)$ delivered through the mouthto-mask device to the lung model resulted in an $\mathrm{FiO}_{2}$ 

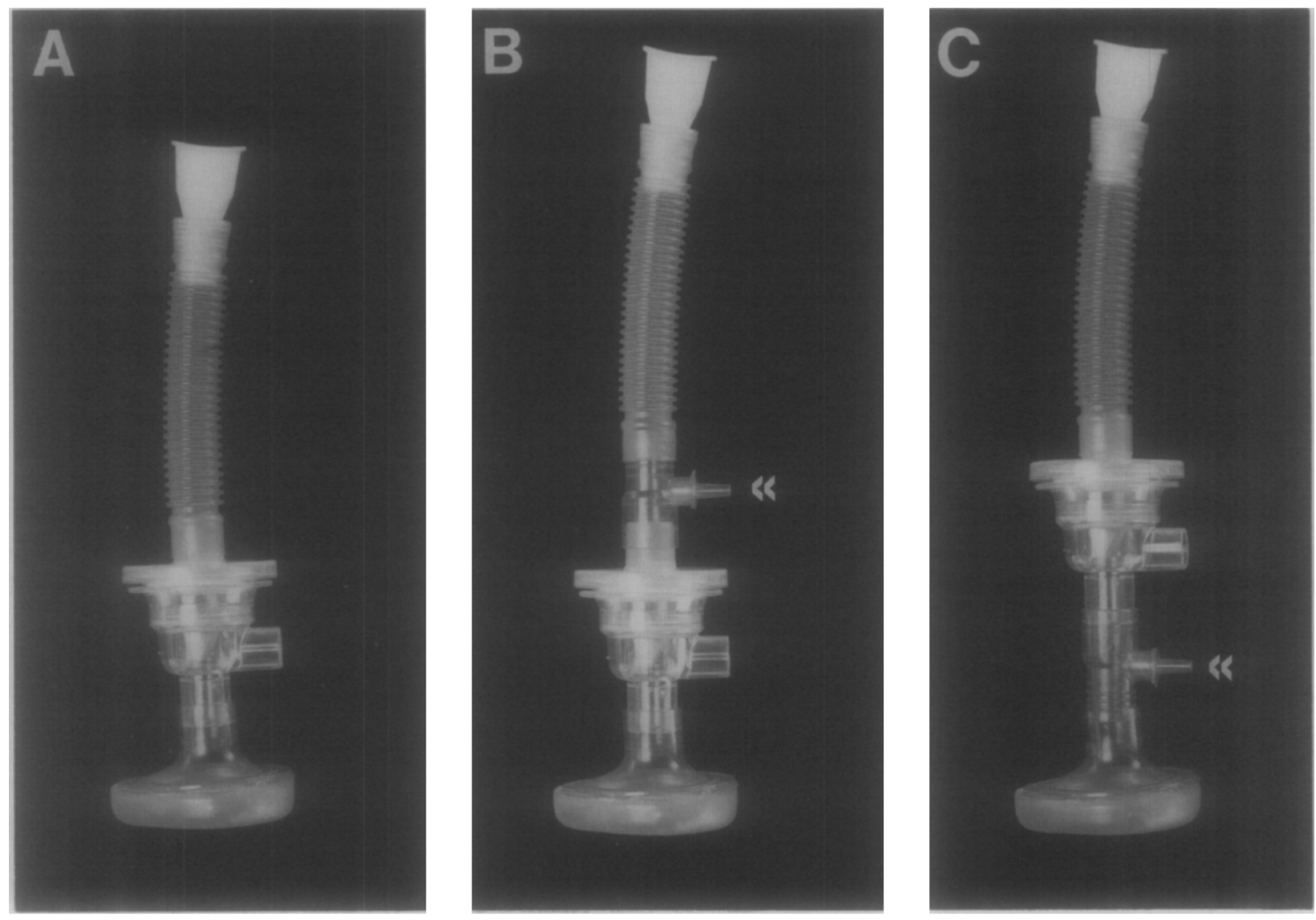

Figure 1. Panel A shows the mouth-to-mask device as supplied by the manufacturer. Panel B shows the device modified with the supplemental oxygen port (arrow) positioned between the mouthpiece and the one-way valve. With the supplemental oxygen port inserted at this location, "stacking of the breaths" occurred. Panel C shows the device with the supplemental oxygen port (arrow) positioned between the facemask and the one-way valve.

from .37 to .52 with supplemental oxygen flow of 5 to $15 \mathrm{~L} / \mathrm{min}$. Smaller tidal volumes $(\leq 200 \mathrm{~mL})$ produced an $\mathrm{FiO}_{2}$ from .42 to .62 with a supplemental oxygen flow of 5 to $15 \mathrm{~L} / \mathrm{min}$ (Table 1$)$.

A second factor associated with the delivered $\mathrm{FiO}_{2}$ was the frequency of assisted ventilation. A slower respiratory rate of 12 breaths/min (Table 2) produced an $\mathrm{FiO}_{2}$ that was $15 \%$ to $30 \%$ greater at each of the oxygen delivery rates $(5,10$, and $15 \mathrm{~L} / \mathrm{min})$ than produced with a respiratory rate of 20 breaths/

Table 1. FiO ${ }_{2}$ Delivered at a Respiratory Frequency of 20/min

\begin{tabular}{lccc}
\hline & \multicolumn{3}{c}{$\mathrm{FiO}_{2}$ Delivered $(\times 100)$ with Respiratory Rate $=20$} \\
\cline { 2 - 4 } $\begin{array}{l}\mathrm{V}(\mathrm{mL}) \\
\text { Delivered }\end{array}$ & $5 \mathrm{~L} / \mathrm{min}$ & $10 \mathrm{~L} / \mathrm{min}$ & $15 \mathrm{~L} / \mathrm{min}$ \\
\hline 50 & $54.7 \pm 0.20$ & $57.3 \pm 0.21$ & $61.9 \pm 0.36$ \\
100 & $52.7 \pm 0.08$ & $55.4 \pm 0.17$ & $57.9 \pm 0.05$ \\
200 & $42.1 \pm 0.27$ & $48.7 \pm 0.11$ & $53.7 \pm 0.08$ \\
300 & $38.6 \pm 0.06$ & $46.4 \pm 0.12$ & $51.8 \pm 0.00$ \\
400 & $38.4 \pm 0.05$ & $46.4 \pm 0.06$ & $51.5 \pm 0.05$ \\
500 & $38.0 \pm 0.00$ & $46.2 \pm 0.04$ & $51.6 \pm 0.06$ \\
600 & $37.5 \pm 0.04$ & $45.9 \pm 0.08$ & $51.2 \pm 0.06$ \\
700 & $37.0 \pm 0.00$ & $45.5 \pm 0.04$ & $47.0 \pm 0.10$ \\
\hline
\end{tabular}

All comparisons of $\mathrm{FiO}_{2}$ Delivered for the same $V_{t}$ Delivered and different supplemental oxygen flow rates of groups were statistically significant $(p$ $<0.005)$. 
Table 2. $\mathrm{FiO}_{2}$ Delivered at a Respiratory Frequency of $12 / \mathrm{min}$

\begin{tabular}{lccc}
\hline \multirow{2}{*}{$\begin{array}{l}V_{\mathrm{t}}(\mathrm{mL}) \\
\text { Delivered }\end{array}$} & \multicolumn{3}{c}{$\mathrm{FiO}_{2}$ Delivered $(\times 100)$ with Respiratory Rate $=12$} \\
\cline { 2 - 4 } & $5 \mathrm{~L} / \mathrm{min}$ & $10 \mathrm{~L} / \mathrm{min}$ & $15 \mathrm{~L} / \mathrm{min}$ \\
\hline 50 & $71.2 \pm 0.11$ & $74.7 \pm 0.16$ & $75.3 \pm 0.09$ \\
100 & $65.4 \pm 0.23$ & $71.2 \pm 0.17$ & $72.0 \pm 0.18$ \\
200 & $58.7 \pm 0.27$ & $66.4 \pm 0.15$ & $69.0 \pm 0.06$ \\
300 & $53.1 \pm 0.29$ & $63.2 \pm 0.10$ & $66.6 \pm 0.14$ \\
400 & $49.8 \pm 0.41$ & $60.2 \pm 0.23$ & $64.1 \pm 0.12$ \\
500 & $47.2 \pm 0.29$ & $57.5 \pm 0.16$ & $61.3 \pm 0.11$ \\
600 & $45.5 \pm 0.20$ & $55.2 \pm 0.08$ & $59.2 \pm 0.10$ \\
700 & $44.9 \pm 0.33$ & $55.3 \pm 0.16$ & $59.5 \pm 0.19$ \\
\hline
\end{tabular}

All comparisons of $\mathrm{FiO}_{2}$ Delivered for the same $V_{\mathrm{t}}$ Delivered and different supplemental oxygen flow rates of groups were statistically significant $(p$ $<0.005)$.

min (Table 1). In addition, when maintaining the $V_{t}$ and assisted ventilation rate constant, increasing the supplemental oxygen delivery rate from $5 \mathrm{~L} /$ minute to $15 \mathrm{~L} /$ minute increased the delivered $\mathrm{FiO}_{2}$ by $5 \%$ to $15 \%$ for smaller tidal breaths $(\leq 200 \mathrm{~mL})$ to $22 \%$ in larger tidal breaths $(\geq 300 \mathrm{~mL})$. In no instance did the $\mathrm{FiO}_{2}$ measured through the mouth-to-mask device exceed $80 \%$.

The addition of supplemental oxygen through the mouth-to-mask device augmented the actual tidal volume delivered to the test lung (Table 3). For smaller tidal volumes ( $\leq 200 \mathrm{~mL}$ ), increasing the supplemental oxygen flow from $5 \mathrm{~L} / \mathrm{min}$ to $15 \mathrm{~L} / \mathrm{min}$ significantly increased the actual tidal volume delivered to the lung model from $40 \%$ to $230 \%$.

\section{DISCUSSION}

Safar (4) previously reported that when artificial ventilation was established via the nasal passages, approximately $30 \%$ of patients could not expire because of a flap valve occlusion at the soft palate. We observed a similar circumstance when the supplemental oxygen port was attached above the "duckbill" valve on the mouth-to-mask device. This obstruction in exhalation may result in gastric dilatation, gastric rupture (9), or pneumothorax. Because of the compatibility and standard diameter fittings among respiratory therapy equipment, the supplemental oxygen port may be easily inserted either between the mouth piece and the one-way valve (Figure $1 \mathrm{~B}$ ) or between the face mask and the one-way valve of the mouthto-mask device (Figure 1C). This problem may also exist in other similar mouth-to-mask devices that incorporate a one-way valve system with a supplemental oxygen port.

Respiratory frequency, supplemental oxygen delivery rate, and $V_{\mathrm{t}}$ all influenced the delivered $\mathrm{FiO}_{2}$. This was probably the result of dilution of the reservoir of oxygen within the tubing of this device. When the supplemental oxygen flow remained constant, any increase in respiratory frequency or tidal volume resulted in decreased $\mathrm{FiO}_{2}$ delivered to the lung model. Increasing the supplemental oxygen flow through the mouth-to-mask device resulted in in-

Table 3. Effects of Supplemental Oxygen Flow on the $V_{t}$ Actual to a Pediatric Lung Model

\begin{tabular}{|c|c|c|c|c|c|c|}
\hline $\begin{array}{l}V_{t}(m L) \\
\text { Delivered }\end{array}$ & $\begin{array}{l}V_{1} \text { Actual } \\
(5 \mathrm{~L} / \mathrm{min})\end{array}$ & $\% V_{t}$ Change & $\begin{array}{c}V_{t} \text { Actual } \\
(10 \mathrm{~L} / \mathrm{min})\end{array}$ & $\% V_{t}$ Change & $\begin{array}{l}V_{t} \text { Actual } \\
\text { (15 L/min) }\end{array}$ & $\% V_{t}$ Change \\
\hline 50 & $98 \pm 4.1$ & 96 & $117 \pm 5.2$ & 134 & $168 \pm 7.5$ & 236 \\
\hline 100 & $157 \pm$ & 57 & $195 \pm$ & 95 & $221 \pm 7.5$ & 121 \\
\hline 200 & $278 \pm 7.5$ & 39 & $315 \pm$ & 58 & $405 \pm 5.5$ & 103 \\
\hline 300 & $393 \pm 5.2$ & 31 & $485 \pm 5.5$ & 62 & $553 \pm 8.2$ & 84 \\
\hline 400 & $501 \pm 4.1$ & 25 & $611 \pm 7.5$ & 53 & $746 \pm 24.2$ & 87 \\
\hline 500 & $615 \pm 5.5$ & 23 & $790 \pm 6.3$ & 58 & $910 \pm 6.3$ & 82 \\
\hline 600 & $756 \pm 18.6$ & 26 & $916 \pm 16.3$ & 53 & $1096 \pm 5.2$ & 83 \\
\hline 700 & $876 \pm 5.2$ & 25 & $1176 \pm 5.2$ & 68 & $1231 \pm 24.8$ & 76 \\
\hline
\end{tabular}

$V_{t}$ Delivered is defined as the volume of gas delivered by the ventilator.

$V_{t}$ Actual is the total volume measured by serial measurements to the test lung.

All comparisons of $V_{t}$ Actual (for $V_{t}$ Delivered) at different oxygen flow rates were statistically significant $(p<0.005)$. 
creased delivered $\mathrm{FiO}_{2}$. At tidal breaths less than 100 $\mathrm{mL}$, increasing the oxygen flow rate from 5 to $15 \mathrm{~L} /$ min changed $\mathrm{FiO}_{2}$ only $5 \%$ to $7 \%$. However, at these tidal volumes $\left(V_{\mathrm{t}} \leq 100 \mathrm{~mL}\right)$, an increase in the supplemental oxygen flow resulted in a $100 \%$ to $200 \%$ incrcase in the tidal volume measured in the model. Because of these unpredicted increases in the actual tidal volumes delivered, it would be important for rescuers to continuously monitor chest excursion when supplemental oxygen is administered to determine the effects of each delivered breath.

The results of this study also indicate that when supplemental oxygen is delivered at a flow rate of 15 $\mathrm{L} / \mathrm{min}$, an $\mathrm{FiO}_{2} \leq .60$ results. Although a greater $\mathrm{FiO}_{2}$ can be achieved with ventilation rates of 12 breaths/min, current guidelines established by the American Heart Association recommend a respiratory rate of approximately 16 to 20 breaths/min (5). Because of the potential risk of gastric dilatation, gastric perforation, or pneumothorax caused by the addition of supplemental oxygen we suggest that for infants, supplemental oxygen flow rates be limited to $5 \mathrm{~L} / \mathrm{min}$ when using this device, since little increase in $\mathrm{FiO}_{2}$ is achieved beyond this flow rate. Finally, we recommend that additional studies of similar devices be performed to: 1) examine the potential for adverse consequences resulting from product design or inhouse modifications prior to pediatric use, and 2) determine the actual $\mathrm{FiO}_{2}$ that can be delivered with varying oxygen flows.

\section{REFERENCES}

1. Harrison RR, Maull KI, Keenan RL, Boyan CP. Mouth to mask ventilation: a superior method of rescue breathing. Ann Emerg Med 1998;11:74-6.

2. Hess D, Baran C. Ventilatory volumes using mouth to mouth, mouth to mask and bag valve mask techniques. Am J Emerg Med. 1985;3:292-6.

3. Stahl JM, Cutfield GR, Harrison GA. Alveolar oxygenation and mouth-to-mask ventilation: effects of oxygen insufflation. Anesth Intens Care. 1992;20:177-86.

4. Safar P. Emergency resuscitation. In: Safar P, ed. Respiratory Therapy. Philadelphia: Davies; 1965:80.

5. Guidelines for cardiopulmonary resuscitation and emergency cardiac care. JAMA. 1992;268:2171-2302.
6. Centers for Disease Control. Guidelines f́or pravention of transmission of human immunodeficiency virus and hepatitis $B$ virus to health-care and public safety workers. MMWR. 1989; $38(\operatorname{supp} 6): 1-37$.

7. Sande MA. Transmission of AIDS: the case against casual contagions. N Engl J Med. 1986;314:380-2.

8. Johnston R, Machin JR, MacNeil A. A trew resuscitation apparatus providing 70\% oxygen. Br Med Jour. 1986;292: $1711-12$.

9. Custer JR, Polley TZ, Moler F. Gastric perforation following cardiopulmonary resuscitation in a child: report of a case and review of the literature. Pediatr Emerg Care. 1987;3:24-7. 